\title{
BMJ Open Tunnelled haemodialysis catheter and haemodialysis outcomes: a retrospective cohort study in Zagreb, Croatia
}

\author{
Vedran Pašara, ${ }^{1}$ Bojana Maksimović, ${ }^{1}$ Mihaela Gunjača, ${ }^{1}$ Karlo Mihovilović, \\ Andrea Lončar, ${ }^{2}$ Boris Kudumija, ${ }^{3}$ Igor Žabić, ${ }^{4}$ Mladen Knotek ${ }^{1,5}$
}

To cite: Pašara $V$,

Maksimović B, Gunjača M, et al. Tunnelled

haemodialysis catheter and haemodialysis outcomes: a retrospective cohort study in Zagreb, Croatia. BMJ Open 2016;6:e009757.

doi:10.1136/bmjopen-2015009757

- Prepublication history for this paper is available online. To view these files please visit the journal online (http://dx.doi.org/10.1136/ bmjopen-2015-009757).

Received 19 August 2015 Revised 7 March 2016 Accepted 15 April 2016

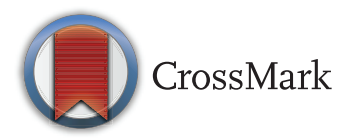

${ }^{1}$ Renal Division, Department of Medicine, University Hospital Merkur, Zagreb Croatia

${ }^{2}$ Renal Division, Department of Medicine, General Hospital Sisak, Sisak, Croatia

${ }^{3}$ Polyclinic for Internal

Medicine and Dialysis

Avitum, Zagreb, Croatia

${ }^{4}$ Renal Division, Department of Medicine, General Hospital Koprivnica, Koprivnica,

Croatia

${ }^{5}$ University of Zagreb School of Medicine, Zagreb, Croatia

Correspondence to Dr Mladen Knotek; mladen.knotek1@zg.t-com.hr

\section{ABSTRACT}

Objectives: Studies have reported that the tunnelled dialysis catheter (TDC) is associated with inferior haemodialysis (HD) patient survival, in comparison with arteriovenous fistula (AVF). Since many cofactors may also affect survival of HD patients, it is unclear whether the greater risk for survival arises from TDC per se, or from associated conditions. Therefore, the aim of this study was to determine, in a multivariate analysis, the long-term outcome of HD patients, with respect to vascular access (VA).

Design: Retrospective cohort study.

Participants: This retrospective cohort study included all 156 patients with a TDC admitted at University Hospital Merkur, from 2010 to 2012. The control group consisted of 97 patients dialysed via AVF. The groups were matched according to dialysis unit and time of VA placement. The site of choice for the placement of the TDC was the right jugular vein. Kaplan-Meier analysis with log-rank test was used to assess patient survival. Multivariate Cox regression analysis was used to determine independent variables associated with patient survival.

Primary outcome measures: Patient survival with respect to VA.

Results: The cumulative 1-year survival of patients who were dialysed exclusively via TDC was $86.4 \%$ and of those who were dialysed exclusively via AVF, survival was $97.1 \%(p=0.002)$. In multivariate Cox regression analysis, male sex and older age were independently negatively associated with the survival of $\mathrm{HD}$ patients, while shorter HD vintage before the creation of the observed VA, hypertensive renal disease and glomerulonephritis were positively associated with survival. TDC was an independent risk factor for survival of HD patients (HR 23.0, 95\% Cl 6.2 to 85.3 ). Conclusion: TDC may be an independent negative risk factor for HD patient survival.

\section{INTRODUCTION}

The number of patients with end-stage renal disease (ESRD) in need of renal replacement therapy increases progressively in Europe and worldwide. ${ }^{1}$ This puts chronic kidney

\section{Strengths and limitations of this study}

- This is a retrospective cohort study in which well matched patients followed by multiple dialysis centres were included. Therefore, study results account for variations in routine patient care at different centres and are reflective of real-life practice. This is important, because a prospective randomised trial comparing patient survival with respect to vascular access type (arteriovenous fistula and tunnelled dialysis catheter) is highly unlikely.

- Main outcomes (patient and vascular access survival) were analysed by multivariate analysis.

- The main limitation of this study is its retrospective and non-randomised design. However, the two patient groups were well matched in the majority of variables that may have affected the outcome.

disease (CKD) among the significant factors of morbidity and mortality, and represents a growing public health issue.

In patients on haemodialysis (HD) treatment, possible long-term vascular access (VA) types are: arteriovenous fistula (AVF), arteriovenous graft (AVG) and tunnelled HD central venous catheter (TDC). Since native AVF, described by Brescia and Cimino in 1966, has the longest survival and the lowest frequency of complications among all other types of VA for HD, it should be the first choice for VA whenever possible. ${ }^{1-3}$ However, there are vast differences in the use of certain VA types in different countries and the use of TDC is still noticeably high, in spite of current guidelines. The rate of patients who are dialysed via TDC among all patients on HD varies from only $1.6 \%$ in Japan up to $52 \%$ in Canada. ${ }^{4}$ In Croatia, $\sim 20 \%$ of patients are dialysed via TDC, while the rest are dialysed via AVF (M Knotek, personal communication, 2015). AVG is infrequently used in Croatia. 
Central venous catheters (CVCs) are used for the rapid establishment of adequate VA when there is an urgent need for $\mathrm{HD}$, as a bridge during AVF maturation process and in patients who have eventually exhausted all other VA types. ${ }^{135}$ According to the kidney disease outcomes quality initiative (K/DOQI) guidelines, temporary catheters should be used for up to 1 week, while the use of TDC is recommended in all other cases where catheter use is unavoidable. ${ }^{6}$ TDCs are usually placed according to the modified Seldinger method. ${ }^{7}$ The insertion site of choice should be the right internal jugular vein. ${ }^{8}$ Alternatively, TDCs can be inserted through the subclavian or femoral vein. The subclavian vein should generally be avoided because of the high incidence of stenosis and thrombosis, while the femoral vein should be considered only when all other insertion sites have been excluded. ${ }^{1}$ The advantages of the TDC include the ability to use it immediately after placement, no repeated venipuncture and no haemodynamic consequences, and no need for a vascular surgeon during placement. ${ }^{4}$ Nevertheless, TDCs are associated with significantly higher long-term risk of death, infections, cardiovascular events and hospitalisation in comparison with other VA types. ${ }^{9}$ However, at the same time, some of the associated conditions and diseases affect patient survival, as well as VA choice and survival. Therefore, although many studies show that TDCs are associated with poorer patient survival, it is not entirely clear whether the risk arises from the TDC exclusively, or from the associated conditions and diseases that are often present in patients who are dialysed via TDC. ${ }^{9} 10$

The aim of this study was to determine HD patient and VA survival with respect to VA type.

\section{PATIENTS AND METHODS}

\section{Patients}

This retrospective cohort study was approved by the Hospital Ethics Committee of the University Hospital Merkur, Zagreb, Croatia. Patients gave their written informed consent for anonymised HD data collection for research purposes. We analysed the survival of patients dialysed via a TDC in comparison with a group of patients who were dialysed via an AVF. We also analysed TDC survival. The study included a total of 253 patients who were treated with $\mathrm{HD}$ in 21 dialysis centre in Croatia; median 16 (IQR 10, 21) per centre. With respect to VA, the TDC:AVF ratio was approximately 2:1. The study subjects were selected to include all 156 patients who received a total of 190 TDC at the Renal Division in University Hospital Merkur, from the beginning of 2010 to the end of 2012. Then, 97 patients who were dialysed via AVF were selected from the same dialysis centres. Eligible patients dialysed via AVF had to start with HD treatment at about the same time as patients dialysed via TDC. The insertion site of choice for the TDC was the right jugular vein. Other sites were used in case of inability to use the right jugular vein or when exchanging over a previously inserted TDC in another vein. All TDCs were manufactured by Medcomp Inc (Harleysville, Pennsylvania, USA). For an internal jugular and subclavian approach, either SST28SE or SST32SE catheters were used, while SST40SE catheters were used for a femoral approach. All catheters were $14 \mathrm{Fr}$.

\section{Methods}

Data were collected from the Renal Division TDC placement programme database and by a questionnaire sent to the $21 \mathrm{HD}$ centres where patients underwent TDC placement procedure in our division. In the questionnaire, we asked for the following information: demographic data, the date of first HD, history of a temporary CVC before the observed TDC, history of an attempt to create an AVF or history of a functional AVF that ceased to function, the cause of $\mathrm{CKD}$, concomitant diseases, history of catheter sepsis, history of an infection of the TDC tunnel, whether there were problems with wound healing after TDC placement, whether there were mechanical problems with the TDC and what solution the TDC problem was usually solved with on the completion of HD treatment. If the TDC was functional, information on the blood pump speed, and on arterial and venous pressure during HD treatment, was inquired about. If TDC ceased to function, we recorded the date of cessation of TDC function, the reason for cessation of TDC function, current VA if the patient was still treated with $\mathrm{HD}$, the date of transplantation if the patient underwent a kidney transplantation and the date of death if the patient died. A similar, modified questionnaire was used to collect data about patients who were dialysed via AVF.

\section{Statistical analysis}

Numerical data are presented as mean $\pm \mathrm{SD}$ in case of continuous variables with normal distribution or as median with IQR in case of non-normal distribution. The difference between two groups regarding continuous variables was tested with Student's t test in normal distributed variables or with Mann-Whitney's $\chi^{2}$ test. Survival analysis, which included patient survival, overall VA survival and death-censored VA survival, was performed using Kaplan-Meier analysis. Univariate and multivariate Cox regression were performed to determine variables independently associated with patient and VA survival. All variables that were associated with respective outcome in bivariate analysis $($ at $p \leq 0.1)$ were included in the multivariate Cox regression. Results are presented as HR with the corresponding 95\% CI. Statistical significance was considered at $p$ value $<0.05$. All statistical analyses were performed using SPSS V.17.0.

\section{RESULTS}

\section{Characteristics of patients dialysed via TDC}

Patient characteristics are shown in table 1 . There were 156 patients dialysed via TDC. The cause of ESRD was 
Table 1 Characteristics of patients

\begin{tabular}{|c|c|c|c|c|}
\hline & All patients & TDC & AVF & p Value \\
\hline Age of patients at initiation of HD treatment (years) ${ }^{*}$ & $62.7 \pm 14.0$ & $62.1 \pm 14.4$ & $63.9 \pm 13.2$ & 0.215 \\
\hline Age of patients at VA creation (years) ${ }^{\star}$ & $63.8 \pm 13.9$ & $63.7 \pm 14.2$ & $64.0 \pm 13.4$ & 0.737 \\
\hline Age of patients at end of follow-up (years) ${ }^{*}$ & $65.8 \pm 13.9$ & $65.2 \pm 14.3$ & $66.9 \pm 12.9$ & 0.248 \\
\hline Sex (male/female) & $152 / 101$ & $88 / 68$ & $64 / 33$ & 0.081 \\
\hline HD vintage (days)† & $607(335,1088)$ & $658(374,1114)$ & $536(320,1139)$ & 0.836 \\
\hline HD vintage before observed VA creation (days) $\dagger$ & $50(5,348)$ & $204(33,799)$ & $7(0,66)$ & $<0.001$ \\
\hline Diabetes mellitus & $42.7 \%$ & $44.2 \%$ & $40.2 \%$ & 0.464 \\
\hline Coronary heart disease & $20.6 \%$ & $20.5 \%$ & $20.6 \%$ & 0.851 \\
\hline Stroke & $11.9 \%$ & $16.7 \%$ & $4.1 \%$ & 0.001 \\
\hline Peripheral vascular disease & $20.2 \%$ & $19.9 \%$ & $20.6 \%$ & 0.902 \\
\hline Peripheral artery revascularisation & $6.3 \%$ & $6.4 \%$ & $6.2 \%$ & 0.228 \\
\hline Partial or total limb amputation & $14.2 \%$ & $15.4 \%$ & $12.4 \%$ & 0.599 \\
\hline
\end{tabular}

diabetic nephropathy in $42.3 \%$ of patients, hypertensive kidney disease in 23.1\%, glomerulonephritis in $9.6 \%$, polycystic kidney disease in $5.8 \%$ and other diseases in $19.2 \%$ of patients. Temporary dialysis catheter use prior to the observed TDC was noted in $69.9 \%$ of patients, $20.5 \%$ had previous TDC and $50.6 \%$ had an attempt to create an AVF or an AVF that ceased to function. During follow-up, $152(97.4 \%)$ patients were dialysed via TDC exclusively, while $4(2.6 \%)$ switched to AVF.

\section{Characteristics of patients dialysed via AVF}

There were 97 patients dialysed via AVF. The cause of ESRD was diabetic nephropathy in $40.2 \%$ of patients, hypertensive kidney disease in $20.6 \%$, glomerulonephritis in $11.3 \%$, polycystic kidney disease in $10.3 \%$ and other diseases in $17.5 \%$ of patients. An attempt to create an AVF or an AVF that ceased to function prior to the observed AVF was seen in $23.7 \%$ of patients. During follow-up, $91(93.8 \%)$ patients were dialysed via AVF exclusively, while $6(6.2 \%)$ switched to a TDC. Patient characteristics are also shown in table 1.

\section{Patient survival}

Patient survival is shown in figure 1A. Cumulative 1-year overall patient survival since the initiation of HD treatment was $93.2 \%$. In univariate analysis of risk factors for the overall patient survival, there were eight negative risk factors: TDC as current VA $(\mathrm{p}=0.001)$, TDC as an exclusive VA $(p=0.001)$, male gender $(p=0.065)$, older age at the initiation of $\mathrm{HD}$ treatment $(\mathrm{p}=0.006)$, concomitant diabetes mellitus $(\mathrm{p}=0.021)$, stroke in patient's history $(\mathrm{p}=0.028)$, concomitant coronary heart disease $(p=0.017)$ and prior peripheral artery revascularisation $(p=0.028)$. Factors positively associated with overall patient survival were shorter HD vintage prior to the observed VA ( $p=0.004)$ and an attempt to create an AVF or history of an AVF that ceased to function prior to the current VA $(p=0.037)$. With respect to ESRD, hypertensive renal disease $(p=0.001)$ and glomerulonephritis
( $p=0.002)$ were positively associated with overall patient survival. The results of univariate analysis are shown in table 2. In the multivariate Cox regression, two factors turned out as independent negative risk factors for overall patient survival: male gender $(p=0.012)$ and older age at the initiation of HD treatment $(p=0.037)$. Shorter HD vintage prior to the observed VA $(\mathrm{p}<0.001)$, hypertensive renal disease $(\mathrm{p}=0.002)$ and glomerulonephritis $\quad(\mathrm{p}=0.018)$ were independently positively associated with overall patient survival. TDC was independently negatively associated with patient survival in the multivariate analysis (HR 23.0, 95\% CI 6.2 to 85.3).

Patient survival with respect to VA is shown in figure 1B. Cumulative 1-year survival of patients who were dialysed exclusively via TDC was $91.2 \%$ and of those who were dialysed exclusively via AVF, 97.1\% ( $p=0.001)$. With respect to VA conversion, 1-year survival of patients who were converted from AVF to TDC was $95 \%$ ( $p=0.102$ in comparison with $\mathrm{AVF}$ as an exclusive VA; $\mathrm{p}=0.002$ in comparison with TDC as an exclusive VA).

In univariate analysis of risk factors for the survival of patients who were dialysed exclusively via TDC, there were four negative risk factors: male gender $(p=0.010)$, concomitant diabetes mellitus $(\mathrm{p}=0.006)$, concomitant coronary artery disease $(p=0.004)$ and prior peripheral artery revascularisation $(\mathrm{p}=0.003)$. Factors positively associated with survival were shorter HD vintage prior to the current VA $(\mathrm{p}<0.001)$, an attempt to create an AVF or an AVF that ceased to function prior to the current VA $(\mathrm{p}=0.001)$, hypertensive renal disease $(\mathrm{p}=0.001)$ and glomerulonephritis $(\mathrm{p}=0.006)$. The results of univariate analysis are shown in table 2. In the multivariate Cox regression, only male gender turned out as an independent negative risk factor $(\mathrm{p}=0.019)$, while shorter HD vintage prior to the current VA $(p<0.001)$, an attempt to create an AVF or an AVF that ceased to function prior to the current VA $(p=0.039)$ and hypertensive kidney disease as the cause of ESRD were independently positively associated with survival. 

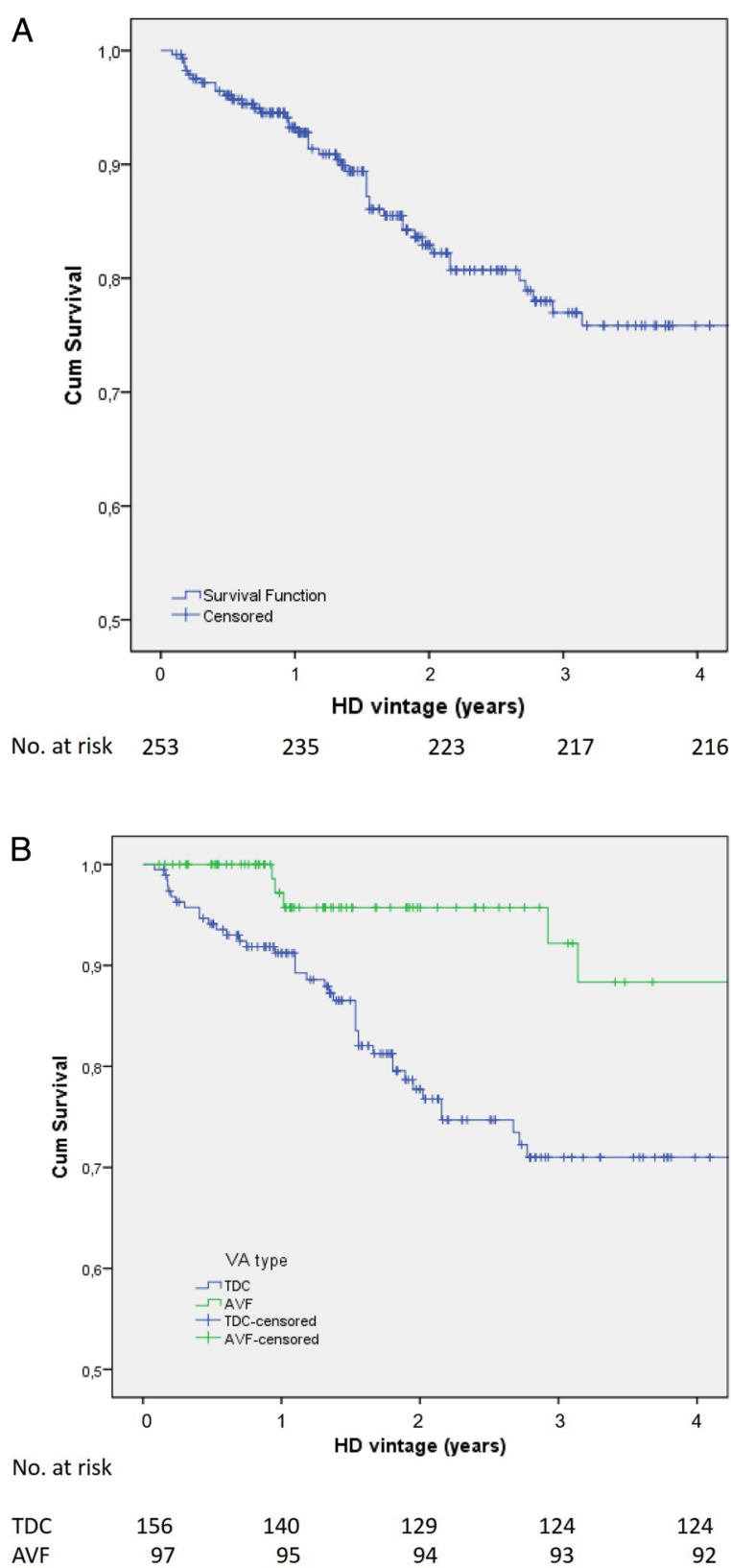

Figure 1 (A) Kaplan-Meier curve for overall HD patient survival. HD, haemodialysis (B) Kaplan-Meier curve for HD patient survival with respect to vascular access. AVF, arteriovenous fistula, TDC, tunnelled haemodialysis catheter; VA, vascular access.

\section{VA survival}

Among the total of 190 TDCs, $124(65.3 \%)$ were placed de novo. Altogether, $58 \%$ of TDCs were placed in the right jugular vein, $11.2 \%$ in the left jugular vein, $17.6 \%$ in the right subclavian vein, $8.5 \%$ in the left subclavian vein, $2.7 \%$ in the right femoral vein and $2.1 \%$ in the left femoral vein. The most frequent long-term complications were TDC thrombosis and infection; $6.8 \%$ of infections led to TDC-associated sepsis and $6.3 \%$ were tunnel infections. Of these, $35.3 \%$ of infections were cured without catheter removal. The TDC was replaced in $47.1 \%$ of infection cases and permanently removed in
$5.9 \%$ of cases. Of the infections, $11.8 \%$ ended in a lethal outcome. The wound healing problems after TDC placement occurred in $5.8 \%$ of patients. Mechanical problems (rupture or separation of catheter lines, puncture or rupture of the clamp or cap) were reported in $7 \%$ of cases. The mean blood pump speed for TDCs in use was $288 \pm 36 \mathrm{~mL} / \mathrm{min}$, mean pressure in the venous line of the dialysis machine was $158 \pm 35 \mathrm{~mm} \mathrm{Hg}$ while mean pressure in the arterial line was $-184 \pm 39 \mathrm{~mm} \mathrm{Hg}$. TDCs were closed with sodium citrate (Duraloc) exclusively in $20.3 \%$ of cases, and in $67.4 \%$ cases, with heparin exclusively, the rest were closed either with sodium citrate or with heparin. During HD treatment it was necessary to switch TDC lines every time in $10.5 \%$ of TDCs, occasionally in $62.1 \%$ and never in $27.4 \%$. During this monitoring process, $50 \%$ of TDCs ceased to function. The causes of cessation are shown in table 3 .

TDC death-censored survival is shown in figure 2 . One-year death-censored TDC survival was $76.7 \%$. In univariate analysis, there were four risk factors negatively associated with TDC survival: an attempt to create an AVF or an AVF that ceased to function prior to the current VA $(p=0.010)$, TDC-associated sepsis $(p<0.001)$, tunnel infection $(p<0.001)$ and mechanical problems with TDCs $(p<0.001)$. In the multivariate Cox regression, an attempt to create an AVF or an AVF that ceased to function prior to the current VA $(p=0.014)$, mechanical problems with the TDC $(p=0.002)$ and TDC line puncture or rupture $(p=0.001)$ were independently negatively associated with TDC deathcensored survival.

The mean blood pump speed for AVF in use was 318 $\pm 36 \mathrm{~mL} / \mathrm{min}$, mean pressure in the venous line of the dialysis machine was $137 \pm 32 \mathrm{~mm} \mathrm{Hg}$, while mean pressure in the arterial line was $-154 \pm 37 \mathrm{~mm} \mathrm{Hg}$. During this monitoring process, $13.4 \%$ of AVFs ceased to function. The causes of cessation are shown in table 4 .

AVF death-censored survival is shown in figure 2. One-year death-censored AVF survival was 96\%. In univariate analysis, male gender was negatively associated with AVF death-censored survival $(\mathrm{p}=0.004)$. No variable was independently associated with death-censored AVF survival in multivariate Cox regression.

VA death-censored survival (both TDC and AVF) is shown in figure 2. In univariate analysis, there were three factors negatively associated with VA death-censored survival: TDC as VA type $(p<0.001)$, an attempt to create an AVF or an AVF that ceased to function prior to the observed VA $(p<0.001)$ and TDC as an exclusive VA $(p<0.001)$. In multivariate Cox regression, $\mathrm{AVF}$ as an exclusive VA was independently positively associated with VA survival $(p<0.001)$.

\section{DISCUSSION}

This analysis defined factors associated with VA and patient survival in a real-life situation, in a patient population treated in 21 dialysis centres across Croatia. The cause of ESRD in a studied group of patients completely 
Table 2 Patient survival—-the results of univariate and multivariate analysis

\begin{tabular}{|c|c|c|c|c|c|}
\hline & $\begin{array}{l}\text { 1-year } \\
\text { survival (\%) }\end{array}$ & $\begin{array}{l}\text { 2-year } \\
\text { survival (\%) }\end{array}$ & p Value & HR (95\% Cl) & p Value \\
\hline \multicolumn{6}{|l|}{ VA type } \\
\hline TDC & 91.2 & 77.7 & $0.001^{*}$ & $3.8(1.6$ to 8.9$)$ & 0.002 \\
\hline AVF & 97.2 & 95.7 & & & \\
\hline \multicolumn{6}{|l|}{ Sex } \\
\hline Male & 91.1 & 79.0 & $0.065^{\star}$ & $1.7(0.9$ to 3.2$)$ & 0.069 \\
\hline Female & 96.5 & 89.0 & & & \\
\hline \multicolumn{6}{|c|}{ An attempt to create an AVF or an AVF that ceased to function prior to the observed VA } \\
\hline Yes & 95.7 & 87.4 & $0.037^{\star}$ & $1.8(1.1$ to 3.1$)$ & 0.040 \\
\hline No & 91.3 & 78.6 & & & \\
\hline \multicolumn{6}{|l|}{ Concomitant diabetes mellitus } \\
\hline Yes & 91.2 & 76.7 & $0.021^{*}$ & $0.5(0.3$ to 0.9$)$ & 0.023 \\
\hline No & 94.8 & 87.5 & & & \\
\hline \multicolumn{6}{|l|}{ Stroke in patient's history } \\
\hline Yes & 94.6 & 72.9 & $0.028^{*}$ & $0.5(0.3$ to 0.9$)$ & 0.031 \\
\hline No & 93.0 & 84.9 & & & \\
\hline \multicolumn{6}{|l|}{ Concomitant coronary heart disease } \\
\hline Yes & 93.2 & 68.9 & $0.017^{\star}$ & $0.5(0.3$ to 0.9$)$ & 0.019 \\
\hline No & 93.3 & 88.2 & & & \\
\hline \multicolumn{6}{|l|}{ Peripheral artery revascularisation } \\
\hline Yes & 100 & 57.9 & $0.028^{*}$ & $0.5(0.2$ to 0.9$)$ & 0.033 \\
\hline No & 92.7 & 86.2 & & & \\
\hline \multicolumn{6}{|l|}{ VA conversion } \\
\hline A & 86.4 & 64.8 & $<0.001^{\star}$ & $2.8(1.5$ to 5.0$)$ & 0.001 \\
\hline B & 97.1 & 95.5 & & & \\
\hline C & 95.0 & 86.5 & & & \\
\hline Hypertensive kidney disease & 96.0 & 96.0 & $<0.001^{*}$ & $0.2(0.1$ to 0.5$)$ & 0.002 \\
\hline Glomerulonephritis & 100 & 100 & $<0.001^{*}$ & $0(0$ to 0.3$)$ & 0.018 \\
\hline $\begin{array}{l}\text { The age of patients at the initiation of HD } \\
\text { treatment (years) }\end{array}$ & & & & $1.0(1$ to 1.1$)$ & 0.037 \\
\hline $\begin{array}{l}\text { Time from the initiation of HD treatment to the } \\
\text { observed VA creation (months) }\end{array}$ & & & & $0.8(0.7$ to 0.9$)$ & 0.006 \\
\hline
\end{tabular}

coincided with Croatian Registry of Renal Replacement Therapy data. ${ }^{11}$ The frequency of concomitant diseases was similar to that in other developed countries. One-year patient survival in this study was excellent, probably reflecting good HD care in Croatia. Female gender was independently positively associated with overall patient survival. This was previously shown in the

\section{Table 3 Causes of TDC function cessation}

\begin{tabular}{lc}
\hline Cause & N (\%) \\
\hline Death of a patient & $37(43.0)$ \\
TDC thrombosis & $14(16.3)$ \\
TDC infection & $9(10.5)$ \\
VA conversion from TDC to AVF & $8(9.3)$ \\
Kidney transplantation & $6(7.0)$ \\
Recovery of renal function & $2(2.3)$ \\
Catheter fell out & $1(1.2)$ \\
\hline AVF, arteriovenous fistula; TDC, tunnelled haemodialysis catheter; \\
VA, vascular access.
\end{tabular}

Choices for Healthy Outcomes in Caring for ESRD study by Astor et al, ${ }^{12}$ where TDC as current VA, male gender and older age at initiation of HD treatment were independently negatively associated with overall patient survival.

In a recent cohort study of 3752 dialysis patients, 1-year survival of patients who were dialysed via TDC was $75 \%$ and factors independently negatively associated with survival were age at first treatment, late referral, coronary artery disease, peripheral vascular disease and cerebrovascular disease. One-year survival of patients dialysed via AVF was $90 \% .{ }^{13}$ There are several other studies that showed a statistically significant difference in patient survival with respect to VA type. ${ }^{12}{ }^{14}$ Our study largely confirms previously observed statistically significant difference in survival between the two groups of HD patients and in the identified independent risk factors for the survival of patients who were dialysed via TDC. However, our results showed that patients included in this study who were dialysed via TDC and those who were dialysed via AVF had better survival in comparison 


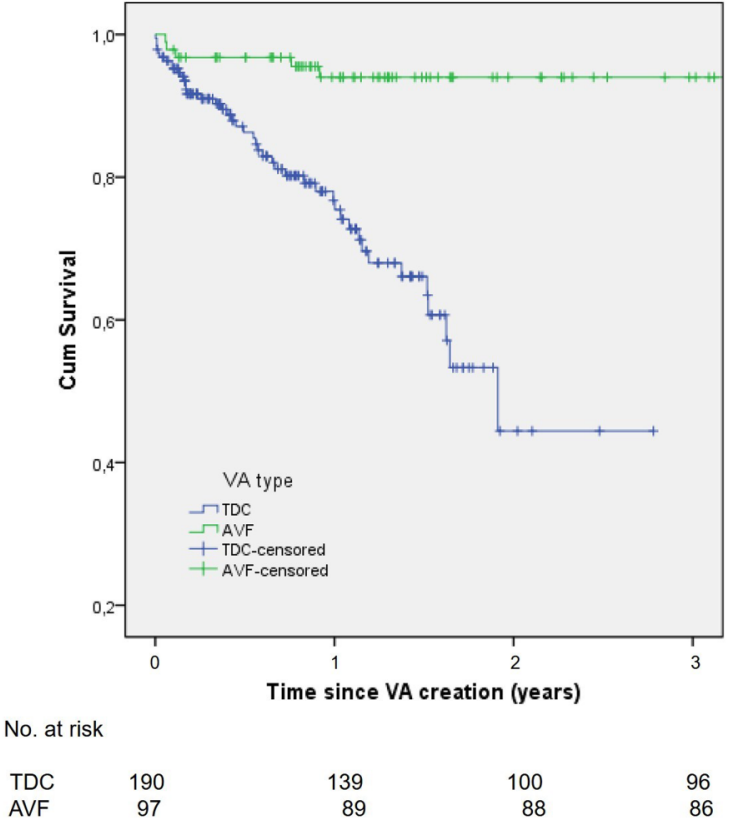

Figure 2 Kaplan-Meier curve for vascular access death-censored survival. AVF, arteriovenous fistula, TDC, tunnelled haemodialysis catheter; VA, vascular access.

with previously published studies. Several studies showed that patient survival is associated with VA conversion and is better in patients who are converted from TDC to AVF during the first year of HD treatment. ${ }^{1015}$ Although our study did not include enough patients who underwent this kind of VA conversion analysis, we showed that survival was not significantly different in patients who were dialysed exclusively via $\mathrm{AVF}$ and those who were converted from AVF to TDC. Therefore, it is likely that there are other factors besides TDC that are responsible for lower survival of patients dialysed exclusively via TDC. Multivariate Cox regression showed that VA type is an independent risk factor for patient survival. The association of VA type with patient survival is controversial. Multiple studies, including ours, suggested negative correlation between TDC and patient survival. ${ }^{9} 1012 \quad 14 \quad 16$ On the other hand, according to several retrospective studies, TDC per se may not be negatively associated with poor patient survival. ${ }^{17} 18$ This issue could be clarified only by prospective randomised control studies, which are difficult to perform.

Studying the association of TDCs with HD patient outcomes is important, because the number of patients who

\section{Table 4 Causes of AVF function cessation}

\begin{tabular}{ll}
\hline Cause & N (\%) \\
\hline Death of a patient & $5(38.5)$ \\
AVF thrombosis & $4(30.8)$ \\
Vein rupture & $2(15.4)$ \\
Difficult AVF puncture or inadequate blood flow & $2(15.4)$ \\
\hline AVF, arteriovenous fistula. &
\end{tabular}

are dialysed via TDC is steadily increasing. ${ }^{19}{ }^{20} \mathrm{~A} \sim 20 \%$ of dialysis patients in Croatia are dialysed via TDC (M Knotek, personal communication). Although K/DOQI guidelines recommend that $<10 \%$ of all patients treated with HD should be dialysed via TDC, this goal remains unachieved. ${ }^{20}$ The number of patients who initiate HD treatment via TDC is also much higher than recommended. ${ }^{19}$ Possible reasons are late referral to a nephrologist, a lack of surgeon availability for AVF creation and an increasing proportion of elderly patients who are not eligible for AVF creation due to their poor blood vessel status. ${ }^{21}$

In one British study of 812 TDC, 1-year deathcensored TDC survival of $61 \%$ was demonstrated. ${ }^{22}$ Another study of 200 Tesio catheters reported a 1-year death-censored catheter survival of $60 \%{ }^{23}$ Our results show significantly better 1-year TDC survival, in comparison with these previously published studies. According to guidelines, the right jugular vein was the insertion site of choice at our centre, but this study did not find a statistically significant difference between the insertion site and TDC survival (data not shown). This may be due to the low power of the study for this analysis, as number of TDC insertions at other sites was low.

In conclusion, we found in the present study that the TDC may be an independent negative risk factor for HD patient survival and that it has a shorter lifetime in comparison with AVF. However, our results stem from a retrospective study, and an adequately powered prospective randomised controlled trial would be necessary to prove causality of the association of TDC with worse HD patient outcome.

Acknowledgements The authors would like to thank the medical staff at all the collaborating dialysis centres for their help with data collection. A portion of this study was accepted for a poster presentation at the 2015 American Society of Nephrology Annual Meeting, San Diego, California, USA.

Contributors VP participated in designing the study, collected and analysed data and wrote the manuscript. BM, MG and KM participated in designing the study and collection of the data, and critically reviewed the manuscript. AL, BK and IŽ participated in designing the study, collected data and critically reviewed the manuscript. MK supervised the design of the study, coordinated and supervised data collection and analysis, and participated in writing the manuscript.

Funding This research received no specific grant from any funding agency in the public, commercial or not-for-profit sectors.

Competing interests None declared.

Patient consent Obtained.

Ethics approval University Hospital Merkur Ethics Review Board.

Provenance and peer review Not commissioned; externally peer reviewed.

Data sharing statement No additional data are available.

Open Access This is an Open Access article distributed in accordance with the Creative Commons Attribution Non Commercial (CC BY-NC 4.0) license, which permits others to distribute, remix, adapt, build upon this work noncommercially, and license their derivative works on different terms, provided the original work is properly cited and the use is non-commercial. See: http:// creativecommons.org/licenses/by-nc/4.0/ 


\section{REFERENCES}

1. Pantelias K, Grapsa E. Vascular access today. World J Nephrol 2012;1:69-78.

2. Vascular Access 2006 Work Group. Clinical practice guidelines for vascular access. Am J Kidney Dis 2006;48(Suppl 1):S176-247.

3. Mihovilovic K, Maksimovic B, Knotek M. Tunneled dialysis catheters placement program in Clinical Hospital Merkur. Acta Med Croatica 2011;65(Suppl 3):54-7.

4. 2010 DOPPS (Dialysis Outcomes and Practice Patterns Study Program) Annual Report. http://www.dopps.org/annualreport/

5. Wadelek J. Haemodialysis catheters. Anestezjol Intens Ter 2010;42:213-17.

6. Hemodialysis Adequacy 2006 Work Group. Clinical practice guidelines for hemodialysis adequacy, update 2006. Am J Kidney Dis 2006;48(Suppl 1):S2-90.

7. Bander SJ, Schwab SJ. Overview of central catheters for acute and chronic hemodialysis access. http://www.uptodate.com/contents/ overview-of-central-catheters-for-acute-and-chronic-hemodialysis + access?source=search_result\&search=Overview+of+central +catheters+for+acute+and+chronic+hemodialysis + access\&selectedTitle $=1 \sim 150$

8. Develter W, De Cubber A, Van Biesen W, et al. Survival and complications of indwelling venous catheters for permanent use in hemodialysis patients. Artif Organs 2005;29:399-405.

9. Ravani P, Palmer SC, Oliver MJ, et al. Associations between hemodialysis access type and clinical outcomes: a systematic review. J Am Soc Nephrol 2013;24:465-73.

10. Lacson $\mathrm{E} \mathrm{Jr}$, Wang W, Lazarus JM, et al. Change in vascular access and mortality in maintenance hemodialysis patients. Am J Kidney Dis 2009;54:912-21.

11. Croatian Registry of Renal Replacement Therapy, Report 2012. http://www.hdndt.org/registar/crt12.html

12. Astor BC, Eustace JA, Powe NR, et al. Type of vascular access and survival among incident hemodialysis patients: the Choices for
Healthy Outcomes in Caring for ESRD (CHOICE) Study. J Am Soc Nephrol 2005;16:1449-55.

13. Polkinghrone KR, McDonald SP, Atkins RC, et al. Vascular access and all-cause mortality: a propensity score analysis. J Am Soc Nephrol 2014;15:477-86.

14. Lok EC, Foley R. Vascular access morbidity and mortality: trends of the last decade. Clin J Am Soc Nephrol 2013;8:1213-19.

15. Bradbury BD, Chen F, Furniss A, et al. Conversion of vascular access type among incident hemodialysis patients: description and association with mortality. Am J Kidney Dis 2009;53:804-14.

16. Sameiro Faria M, Ribeiro S, Costa $E$, et al. Risk factors for mortality in hemodialysis patients. Dis Markers 2013;35:791-8.

17. Di lorio BR, Bellizzi V, Cillo N, et al. Vascular access for hemodialysis: the impact on morbidity and mortality. J Nephrol 2004;17:19-25

18. Duncan ND, Singh S, Cairns TD, et al. Tesio-Caths provide effective and safe long-term vascular access. Nephrol Dial Transplant 2004;19:2816-22

19. Moist LM, Trpeski L, Na Y, et al. Increased hemodialysis catheter use in Canada and associated mortality risk: data from the Canadian Organ Replacement Registry 2001-2004. Clin J Am Soc Nephrol 2008;3:1726-32.

20. Sampathkumar K, Ramakrishnan M, Sah AK, et al. Tunneled centra venous catheters: experience from a single center. Indian $\mathrm{J}$ Nephrol 2011;21:107-11.

21. Ethier J, Mendelssohn DC, Elder SJ, et al. Vascular access use and outcomes: an international perspective from the dialysis outcomes and practice patterns study. Nephrol Dial Transplant 2008;23:3219-26.

22. Fry AC, Stratton J, Farrington $\mathrm{K}$, et al. Factors affecting long-term survival of tunnelled haemodialysis catheters-a prospective audit of 812 tunnelled catheters. Nephrol Dial Transplant 2008;23:275-81.

23. Wang J, LaBerge JM, Chertow GM, et al. Tesio catheter access for long-term maintenance hemodialysis. Radiology 2006;241:284-90. 